\title{
Use of correlation of iron loss and copper loss for improving the efficiency of three phase squirrel cage induction motors
}

\author{
B. B. Saanane, A. H. Nzali \& D. J. Chambega \\ Department of Electrical Power Engineering, \\ University of Dares Salaam, Tanzania
}

\begin{abstract}
So far computation of iron (core) losses in induction motors cannot be performed through exact analytical methods but is dependent mainly on empirical formulae and experience of motor designers and manufacturers. In comparison to copper losses, which are to a larger extent easier to calculate, iron losses are mostly associated with some practical parameters, for example the type of material and manufacturing conditions. This paper proposes a new correlation between these two losses with the aim of getting minimized total machine loss in order to improve the efficiency. A total loss prediction model is developed on a matlab 6.5 platform such that the optimal airgap magnetic flux density and airgap length points are established which offer minimized total loss, $\min \left(P_{f e}+P_{c u}\right)$. These points are then used to reconfigure a new motor geometry with a minimized total loss. The new motor design approach was simulated on a 2D-FEM to analyse the new motor response. Experimental results which agree with the results of the design show an improvement of motor efficiency. Also, empirical formulae are developed and validated which can greatly assist motor designers.

Keywords: total loss model, optimization, analysis, design formulae, motor efficiency.
\end{abstract}

\section{Introduction}

Electrical motors in general, and industry's "workhorse " AC induction motors in particular, represent a great potential and realizable energy savings. Motors account for approximately $64 \%$ of electricity consumption in the US, at a yearly 
cost of US $\$ 112$ billion. Every $1 \%$ reduction in motor demand therefore cuts $0.64 \%$ or US $\$ 716,800,000$ off the industry-wide bill [1].

Motors lose energy in several ways. The difference between the power input and power output make up the motor losses, which are generally defined as noload and load-dependent losses.

The no-load losses consist of the friction and windage loss which come from bearing friction and air resistance of the spinning fan/rotor respectively. Also, included are the iron losses which are a result of a combination of hysteresis and eddy current effects due to the changing magnetic fields in the motor's steel core. The load dependent losses consist of the stator losses (product of stator input current squared and stator resistance at operating temperature), the rotor losses (product of induced rotor current squared and rotor resistance) and stray losses which come from additional harmonics due to the supply and circulating current losses in the magnetic steel and windings.

\section{Statement of the problem}

All losses with the exception of the core losses, can be expressed analytically. But core losses can only be expressed through empirical formulae, as many authors until to-date have found out [2]. This situation is due to the fact that the material used for magnetic circuits of the machines is non-linear. So in reality, it has not been possible to get analytical expressions to fully describe the phenomena of hysteresis and eddy currents in the machine cores.

Therefore, in three phase induction motors, about $16 \%$ of total losses are core losses, while about $48 \%$ are copper losses. Hence, it is still important to continue finding how to reduce iron and copper losses so as to raise the motor efficiency. This paper proposes a new correlation between these two losses with the aim of getting minimized total machine loss in order to improve the efficiency.

\section{The employed methodology}

The parameters of any motor frame including its geometry form the initial data for developing the total loss optimization model. Through the developed model, the airgap magnetic flux density $B_{\delta}$ and airgap diameter (stator bore) $D$ are both varied. As a consequence, also varies the geometry of the stator and rotor teeth, slots and backs so as to achieve minimized total loss $\min \left(P_{f e}+P_{c u}\right)$ in the same motor frame. From this procedure, it is then possible to locate the optimal points of $B$ and $D$ respectively, for the airgap magnetic flux density and airgap diameter. Using these optimal points a new motor geometry is reconfigured which assures a minimized total loss of the motor. This approach is summarized in a flowchart which is given in Figure 1.

The new motor design according to the above approach is simulated on a twodimensional finite element method (2D-FEM) to analyze the new motor response. Experimental results are also compared with the results of the design in 
order to check for any improvement of motor efficiency. Also, empirical formulae are developed and validated which can greatly assist motor designers.

\section{Motor prediction model}

The optimisation was carried out through a model incorporating also, the complete stator and rotor geometry. The model was then implemented on a matlab 6.5 platform.

\subsection{Assumptions for the approximate iron loss prediction model}

Prediction and subsequent optimisation of iron loss and copper loss was achieved by minimizing the losses in different sections of the core through minimization of their magnetic flux densities by influencing on the air gap flux density. The limit of the air gap flux density $\boldsymbol{B}$ for a given maximum induction in the stator and rotor teeth and backs, depended on the thickness of the teeth and the backs. In this model, the parasitic effects were not considered, with the exception of the surface and teeth reluctance losses in the rotor.

Hence, for a given motor geometry and by varying the air gap induction $\boldsymbol{B}$ and air gap diameter $\boldsymbol{D}$, the motor loss prediction model was developed with consideration of the following assumptions: (1) The non-linear magnetic behaviour of the iron material was taken into consideration by allocating a maximum flux density in different iron regions of the machine; (2) The leakage fluxes in the air gap and slots were neglected, such that, all magnetic flux crossing the air gap was assumed to flow radially through the teeth; (3) The overhang effects were neglected; (4) Stray losses were not included in the model; (5) A sinusoidally distributed air gap flux density was assumed; and (6) The current loadings in the stator and rotor were determined by the cooling capacity and the available slot areas in the motor cross-section.

\subsection{Flowchart of optimization for the approximate iron loss prediction model}

The flowchart as shown in Figurel for the approximate motor loss prediction model was developed on the basis of the motor geometry including the simple thermal model of a motor and the empirical iron loss formulae. The initial conditions were considered to be the nominal values of the original motor frame type $160 \mathrm{~L}-4$ for $15 \mathrm{~kW}$. The idea therefore, was to try the motor loss optimisation method on this original motor geometry, in order to get a new geometry with lowered total loss. So, this therefore, could lead to efficiency improvement of the same motor frame size, but with a re-configured geometry.

The iteration was conducted on varying the air gap induction, $\hat{B}_{\delta}$ and air gap diameter, $D$ and also through the logic loops for the model to be able to compute the minimized value of motor loss, $P_{t o t}(B, D)$, of the motor. 


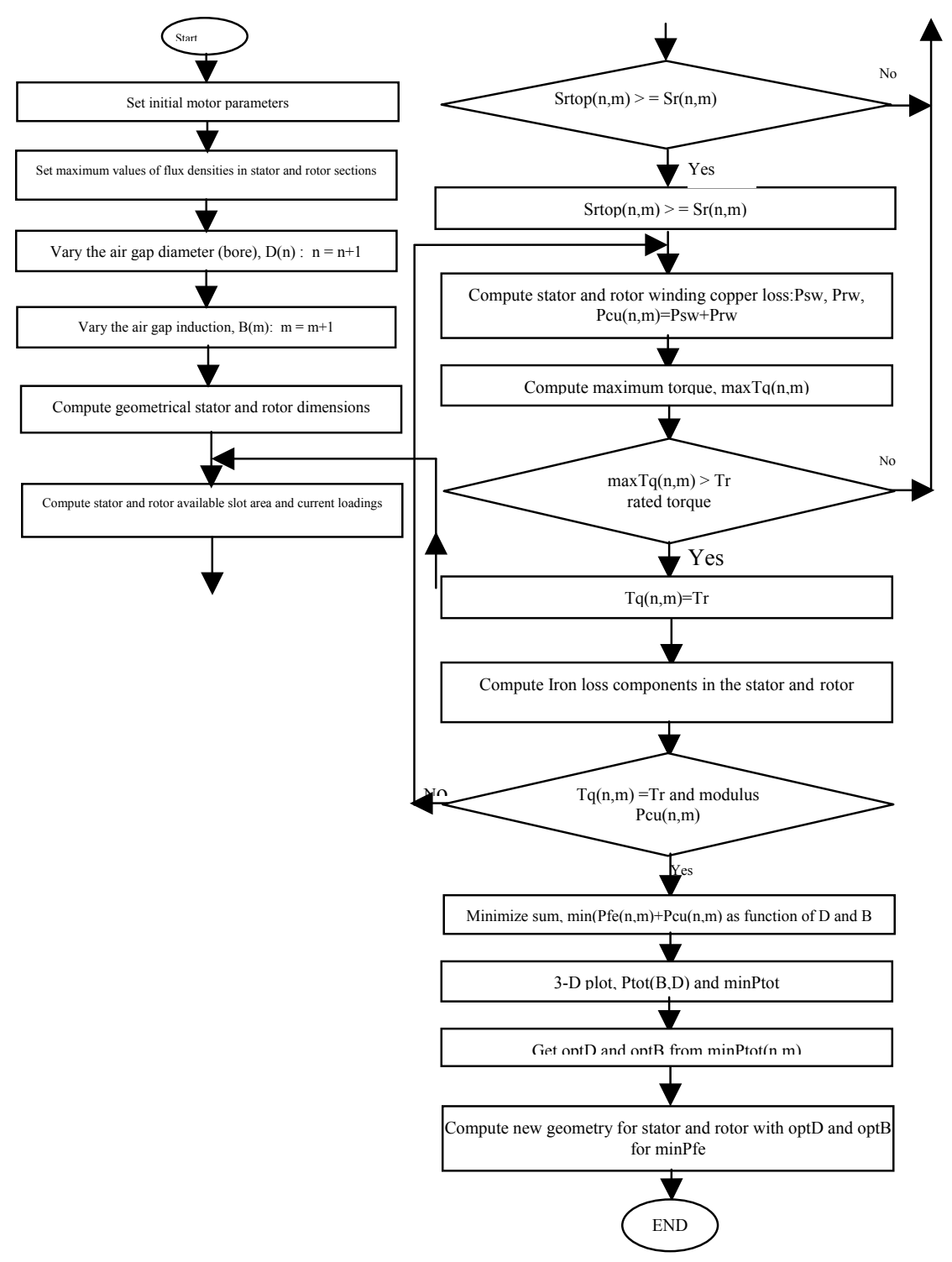

Figure 1: Flowchart of optimisation for the motor loss prediction model.

\subsection{Optimization of motor loss prediction model}

In this approximate motor loss prediction model, optimization of motor loss was achieved by minimizing the losses in different sections of the core by influencing the airgap flux density $\hat{B}_{\delta}$ and air gap diameter $D$. The limit of the air gap 
induction $\hat{B}_{\delta}$ for a given maximum induction in the stator and rotor teeth and back depended on the thickness of the teeth bts, btr and backs hrs, hrr. These geometrical dimensions depended also on the airgap diameter $D$. Therefore, by increasing $\hat{B}_{\delta}$ the available space areas for slots $A_{s s}, A_{s r}$ decreased and as a consequence also, the current loadings $S_{r s}, S_{r r}$ decreased. Conversely, by increasing the current loadings brought about an increase in the slot areas and a reduction in the widths of the teeth and the backs. As a result, the airgap induction $\hat{B}_{\delta}$ decreased. Also, the iron losses were considered together with the copper losses as in a real motor. Implementation of the model was done on the matlab 6.5 platform on the basis of the flowchart shown in Figure 1. Thereafter, the motor loss curve as a function of $\hat{B}_{\delta}$ and $D$ was minimized as shown in Figure 3. In this model, however, the motor for every shaft power was dimensioned by maintaining the same nominal (rated) torque, the same outer diameter of the stator core and the same airgap thickness. This was done so in order to keep the same frame size. Through minimization of $P_{t o t}(B, D)$ the optimal point was located and the corresponding values for $B$ and $D$ were determined as $o p t B$ and $o p t D$. These new values optB and $o p t D$, then facilitated to compute the new motor geometry for stator and rotor cores with a result of reduced motor losses.

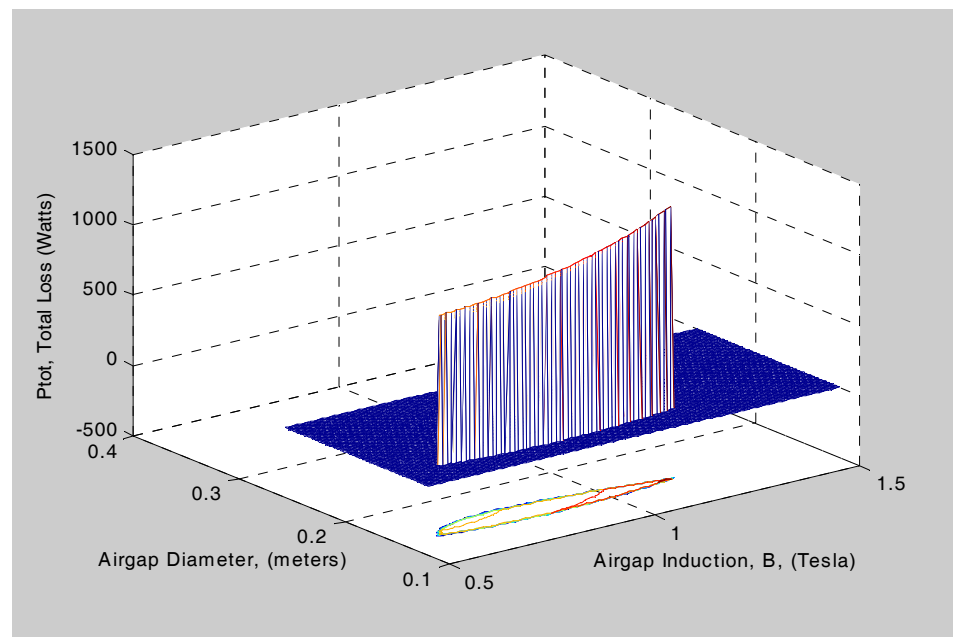

Figure 2: $\quad$ Motor Loss, Ptot, (Watts) for a 15kW motor type M3AP $160 \mathrm{~L}-4$ as a function of Air gap Induction, B, and Air gap Diameter, D.

\subsection{Optimization of motor loss prediction model}

The developed approximate motor loss prediction model was applied to the frame size of a three phase squirrel cage motor, $15 \mathrm{~kW} \mathrm{4-pole.} \mathrm{The} \mathrm{iron} \mathrm{loss}$ correction factors were introduced in the iron loss empirical expressions, in order to account for other loss making mechanisms, like the stray losses which were 
not included in the model. This motor loss prediction model was able to give theoretical results as shown in Figure 3 and Figure 4. From Figure 3, it was possible to locate the point with minimum motor loss, minPtot, and the corresponding values, $o p t B$ and $o p t D$.

Then, values of randomly selected seventeen options around the optimal points $o p t B$ and $o p t D$ were computed and plotted as shown in Figure 4. They were generated through various combinations of peak values of magnetic flux densities in different motor sections for both stator and rotor. Through this procedure could generate a new motor geometry inside the same frame with minimized total loss $\min (P f e+P c u)$.

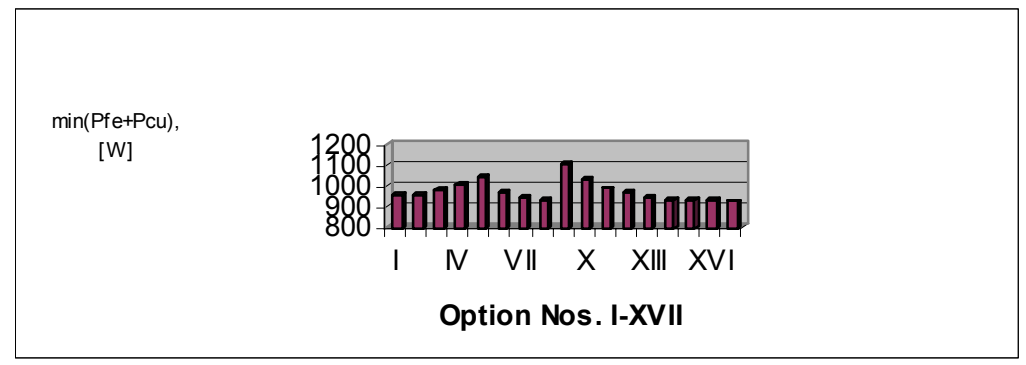

Figure 3: $\quad$ Seventeen options for motor loss optimization on a $15 \mathrm{~kW}, 160 \mathrm{~L}-4$ motor.

\subsection{Formulation of the correlation empirical formula between the iron loss and copper loss}

The statistical analysis of the model results was performed using a software [3]. So, the optimised parameters $B, D, P c u$ and $P f e$ were then statistically analysed. Empirical correlation relationships were therefore formulated as given in Equations (1), (2), (3) and the curve relationship shown in Figure 5:

Following below are the developed novel empirical formulae:

where:

$$
D=a+b B+c B^{2}+d B^{3},
$$

$$
a=4.8121051, b=-22.112476, c=31.935455, d=-18.773035 \text {; }
$$

$\mathrm{D}[\mathrm{m}]$ and $\mathrm{B}[\mathrm{T}]$. The limits are:

$$
\begin{aligned}
0.5700<B< & 0.6900 T \text { and } 0.1580<D<0.1760 m^{\circ} \\
& P_{f e}=a+b B+c B^{2}+d B^{3},
\end{aligned}
$$

where:

$$
a=186363.05, b=-834456.03, c=1248912.5, d=-622984.39 \text {; }
$$

and $P_{f e}[\mathrm{~W}]$ and $\mathrm{B}[\mathrm{T}]$. The limits are:

$$
\begin{gathered}
0.6300<B<0.6900 T \text { and } 539.9300<P_{f e}<573.800 \mathrm{~W} \cdot \\
P_{c u}=a+b P_{f e}+c P_{f e}^{2}+d P_{f e}^{3},
\end{gathered}
$$


where: $\quad a=-4049416.8, b=22282.868, c=-40.851615, d=0.024954481$; and $P_{c u}[\mathrm{~W}]$ and $P_{f e}[\mathrm{~W}]$.

The limits are:

$536.1100<P_{f e}<546.1500 \quad W \quad$ and $382.500<P_{c u}<451.5500 \quad W \cdot$

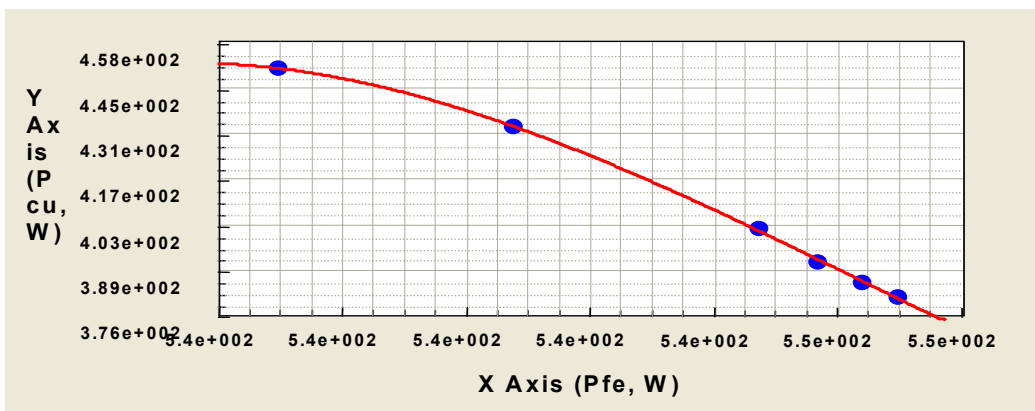

Figure 4: $\quad$ Relationship Pcu vs. Pfe for $15 \mathrm{~kW}$ motor M3AP $160 \mathrm{~L}-4$.
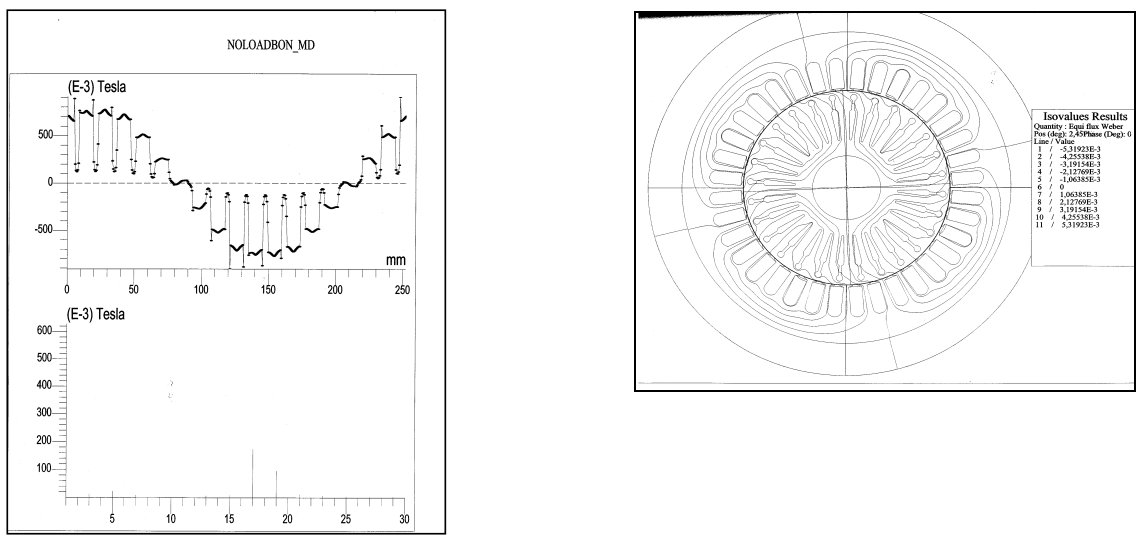

Figure 5: Air gap flux density and the higher harmonics present Figure 6: Chart of magnetic field including the fundamental lines for no-load motor operation. one.

\subsection{The Finite Element Method Analysis of new motor geometry}

The evaluation of electromagnetic field in all the simulations was based on the finite element computation of the unknown represented by the magnetic vector potential, a vector normally oriented to the computation domain, [5].

Two magneto-harmonic models of no-load operation for rated source voltage and frequency were employed: (1) simulation with a value lower than the rated 
slip; and (2) simulation with rated slip and with a value of rotor bar resistivity much larger than the real value; a value $10^{5}$ times greater was used. Both options could give practically the same results, which are shown in Figure 5 and Figure 6. The main numerical results of no-load simulation were: (1) the value of no-load current for each phase was, I10 =18.7A, 19A, 20.9A; (2) stator and rotor iron loss was $343 \mathrm{~W}$.

Table 1: Comparison of results.

\begin{tabular}{|c|c|c|c|c|}
\hline $\begin{array}{l}\text { Motor type } \\
\text { for } \\
\text { ABB } \\
\text { frames }\end{array}$ & $\begin{array}{l}\text { Computed data } \\
\text { from } \\
\text { original geometry }\end{array}$ & $\begin{array}{l}\text { Simulated data } \\
\text { for new geometry } \\
\text { with developed } \\
\text { model }\end{array}$ & $\begin{array}{l}\text { Simulated data } \\
\text { for new geometry } \\
\text { with FEM }\end{array}$ & $\begin{array}{l}\text { Experimental } \\
\text { data } \\
\text { on original motor }\end{array}$ \\
\hline $\begin{array}{l}\text { M3AP } 160 \\
\text { L-4 }\end{array}$ & $\begin{array}{l}\text { A) At unity iron } \\
\text { loss correction } \\
\text { factors: } \\
\text { Kbts }=1, \text { Kbrs }=1, \\
\text { Kbtr }=1, \\
\text { Kbrr }=1 \\
\text { Pcu }=346.74 \mathrm{~W} \\
\text { Pfet }=68.18 \mathrm{~W}, \\
\text { Pfer }=170.35 \mathrm{~W} \\
\text { Ptar }=5.87 \mathrm{~W} \\
\text { Pytr }=77.65 \mathrm{~W} \\
\text { Pexc }=0.71 \mathrm{~W} \\
\text { Pfe }=322.76 \mathrm{~W} \\
\text { Ptot= }=669.50 \mathrm{~W} \\
\\
\text { B) At non-unity } \\
\text { iron loss correction } \\
\text { factors: } \\
\text { Kbts }=1.51, \\
\text { Kbrs }=2.234 \\
\text { Kbrr }=1.52, \\
\text { Kbtr }=1.20 \\
\text { Pcu }=346.74 \mathrm{~W} \\
\text { Pfet }=102.95 \mathrm{~W} \\
\text { Pfer }=380.55 \mathrm{~W} \\
\text { Ptar }=7.05 \mathrm{~W} \\
\text { Pytr }=118.03 \mathrm{~W} \\
\text { Pexc }=0.71 \mathrm{~W} \\
\text { Pfe }=609.29 \mathrm{~W} \\
\text { Ptot }=956.03 \mathrm{~W}\end{array}$ & $\begin{array}{l}\text { A) At unity iron loss } \\
\text { correction factors: } \\
\text { Kbts }=1, \text { Kbrs }=1, \\
\text { Kbtr }=1, \\
\text { Kbrr }=1 \\
\text { Pcu }=383.48 \mathrm{~W} \\
\text { Pfet }=57.86 \mathrm{~W} \\
\text { Pfer }=139.06 \mathrm{~W} \\
\text { Ptar }=10.72 \mathrm{~W} \\
\text { Pytr }=46.47 \mathrm{~W} \\
\text { Pexc }=0.58 \mathrm{~W} \\
\text { Pfe }=254.68 \mathrm{~W} \\
\text { Ptot }=638.16 \mathrm{~W} \\
\\
\text { B) At non-unity } \\
\text { ironloss correction } \\
\text { factors: } \\
\text { Kbts }=1.51, \\
\text { Kbrs }=2.234 \\
\text { Kbrr }=1.52, \\
\text { Kbtr }=1.20 \\
\text { Pcu }=383.48 \mathrm{~W} \\
\text { Pfet }=87.37 \mathrm{~W} \\
\text { Pfer }=310.66 \mathrm{~W} \\
\text { Ptar }=12.86 \mathrm{~W} \\
\text { Pytr }=70.63 \mathrm{~W} \\
\text { Pexc }=0.58 \mathrm{~W} \\
\text { Pfe }=482.09 \mathrm{~W} \\
\text { Ptot }=928.65 \mathrm{~W}\end{array}$ & $\begin{array}{l}\text { A) At unity iron } \\
\text { loss correction } \\
\text { factors: } \\
\text { Kbts=1, Kbrs=1, } \\
\text { Kbtr=1, } \\
\text { Kbrr=1 } \\
\text { Stator iron loss, } \\
207.20 \mathrm{~W} \\
\text { Rotor iron loss, } \\
136 \mathrm{~W} \\
\text { Total iron loss, } \\
343.2 \mathrm{~W}\end{array}$ & $\begin{array}{l}\text { A) Standard } \\
\text { efficiency type } \\
\text { Pcu }=325.24 \mathrm{~W} \\
\\
\text { Pfet }=57.9 \mathrm{~W} \\
\text { Pfer }=180.4 \mathrm{~W} \\
\text { Ptar }=4.60 \mathrm{~W} \\
\text { Pytr }=45.9 \mathrm{~W} \\
\text { Field factor }=1.08 \\
\text { Pfe }=337.09 \mathrm{~W} \\
\text { Ptot }=662.33 \mathrm{~W} \\
\text { No load Iron loss } \\
\text { Calculated }=310 \\
\mathrm{~W} \\
\text { Tested }=262 \mathrm{~W} \\
\text { B) High } \\
\text { Efficiency type } \\
\text { (Eff. } 1 \text { ) } \\
\text { Pcu }=325.24 \mathrm{~W} \\
\text { Pfet }=55.1 \mathrm{~W} \\
\text { Pfer }=171.6 \mathrm{~W} \\
\text { Ptar }=2.00 \mathrm{~W} \\
\text { Pytr }=18.8 \mathrm{~W} \\
\text { Field factor }=2.15 \\
\text { Pfe }=532.05 \mathrm{~W} \\
\text { Ptot= }=857.29 \mathrm{~W}\end{array}$ \\
\hline
\end{tabular}

\section{Discussion of results}

The winding materials are assumed to be copper for the stator winding and aluminium for the rotor winding and the steel sheet material is used for the magnetic circuit. For a given airgap induction and maximum flux densities in the teeth and backs, the copper loss is calculated using the formulae according to Chandur [2].

Through the methodology outlined in sec.3, the developed total loss prediction model made possible to initially locate the optimal points of airgap magnetic induction, airgap diameter and the minimized total loss, $\min (P f e+P c u)$. 
With these points, a new motor geometry was re-configured and verified its performance including comparison with experimental results. The analytical and experimental results are summarized in Table 1.

\section{Conclusion}

In comparing the analytical model results with the experimental data there is a good and acceptable agreement. The model gives a lower value of the total loss than with the results from the original motor frame. So through this motor loss model the motor efficiency can be improved. Therefore, this model and the developed empirical formulae given as equations (1), (2) and (3) are very useful tools to motor designers.

\section{List of symbols}

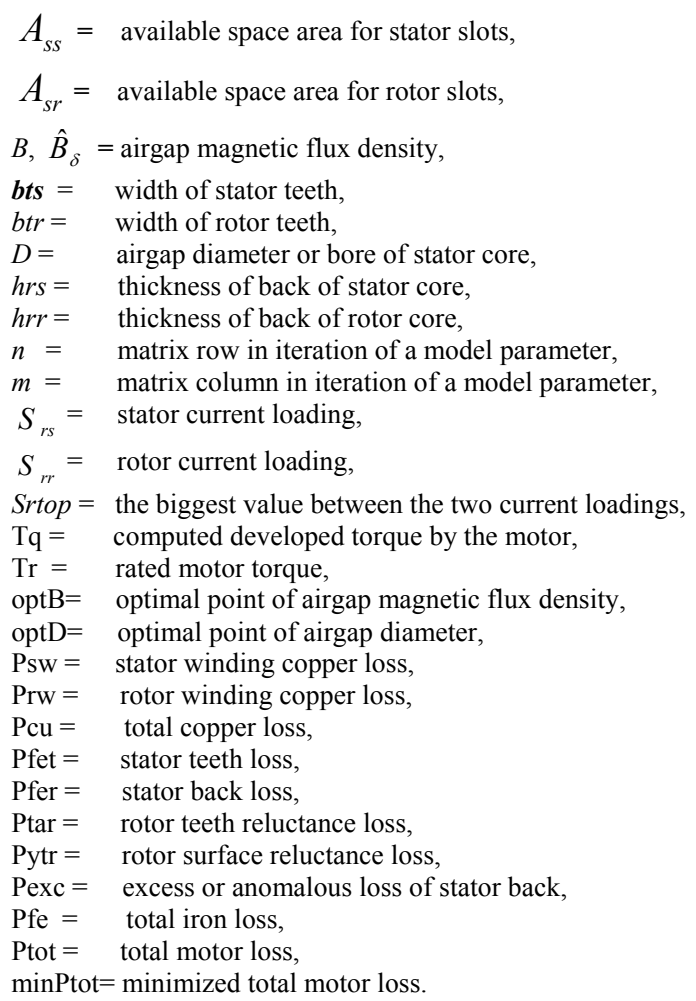

\section{References}

[1] Application Note, "An In-Depth Examination of an Energy Efficiency Technology”, Pacific Gas and Electric Company May 1997. 
[2] Chandur, S. "Electrical machine design and analysis of induction and permanent magnet motors", Department of Electric Power Engineering, Electrical Machines and Power Electronics, Royal Institute of Technology, Stockholm, August 2000.

[3] Chapra S. \& Canale R. "Numerical Methods for Engineers", McGraw 1998.

[4] Electrical Technology, "http://www.very last page of the internet.com/elctromagnetic dv/muller/electrical_gene...16/1/02".

[5] Masato E. and Kenji O. "Designing a low-loss induction motor considering the vector magnetic properties", IEEE Transactions on Magnetics, Vol.38, No.2, pp 877-880, March 2002.

[6] Oriano B., Aldo C., Mario C. and Maurizio R. "Iron losses in Electrical Machines: Influence of different material models", IEEE Transactions on Magnetics, Vol.38, No.2, pp 805-808, March 2002.

[7] Saanane B.B, Nzali A.H and Chambega D.J. "Design Approach of Squirrel Cage Induction Motors by Use of Iron Loss Optimization Method for Improving Efficiency", Electrocomp 2005, Wessex Institute of Technology, WIT Transactions on Modeling and Simulation, Vol. 41, pp 621-629, (C) 2005 WIT Press, UK, March 2005

[8] Stumberger B., Gorican V., Stumberger G., Hamler A., Trlep M. and Jesenik M. "Accuracy of iron loss calculation in electrical machines by using different iron loss models", Journal of Magnetism and Magnetic Materials, pp 254-255, 2003. 